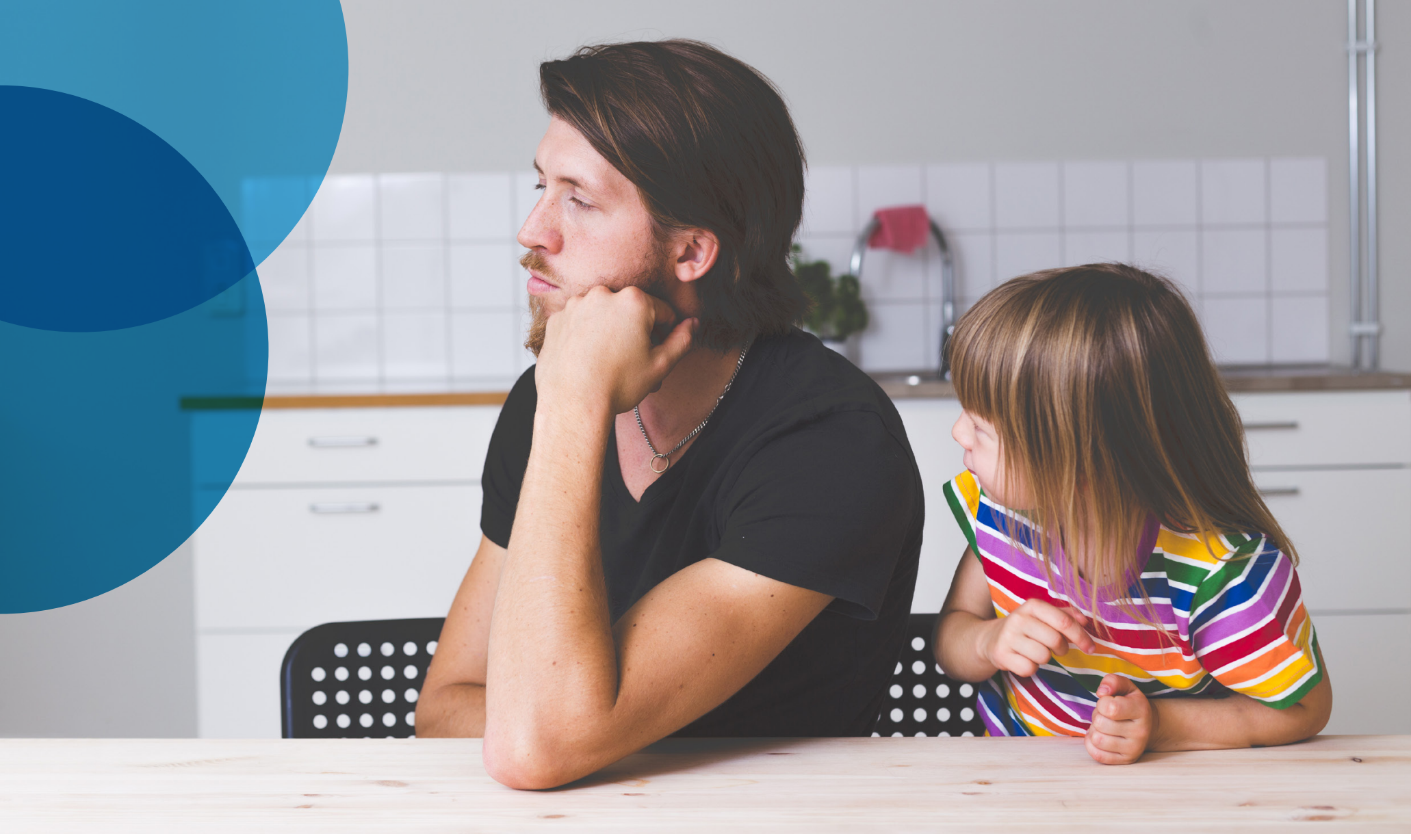

\title{
Insecure paternal attachment confers a high cost on society
}

\author{
By Jessica K. Edwards
}

In 1969, Bowlby proposed that the child-caregiver relationship, established during childhood, can influence child development and behavioural outcomes later in life: a concept known as Attachment Theory'. In support of this theory, many have identified that youth who exhibit externalizing, antisocial behaviours often have an 'insecure' attachment profile ${ }^{2}$ that is characterized by avoidant/dismissive, resistant/ preoccupied or disorganized behaviours ${ }^{3}$. Youth that exhibit such antisocial behaviours can impose a high cost on society due to the need for health, social and economic support in adulthood ${ }^{4-5}$. Now, researchers have studied whether insecure attachment underlying antisocial behaviour contributes to or even adds to these costs.

The study by Bachmann et al. included children exhibiting moderate $(n=85)$ or very high antisocial $(n=89)$ behaviour at age $3-8$ years. The researchers recorded the health and service costs conferred by each child, assessed the level of attachment felt towards the mother and the father, and sought reports of oppositional and conduct problems and delinquent behaviour between ages 9 and 17 . They found that the costs were significantly greater for youth exhibiting insecure attachment than youth exhibiting secure attachment to their caregivers. Interestingly, this cost difference between the two groups was much more pronounced for youth insecurely attached to their fathers than to their mothers. These findings remained statistically significant, even after adjusting for family income and education, intelligence and the severity of antisocial behaviour. The researchers conclude that insecure attachment, especially to fathers, is a significant predictor of public cost in at-risk youth.

In an accompanying commentary, Howard Steele at the Center of Attachment Research, New York explains that early parenting interventions that aim to strengthen the child-caregiver relationship would be likely to improve child outcomes in later life and reduce the cost burden on society associated with insecure attachment. Based on these data, it seems that social policy initiatives that aim to empower fathers in particular, are needed. 


\section{Referring to:}

Bachmann, C.J., Beecham, J., O'Connor, T.G., Scott, A., Briskman, J. \& Scott, S. (2019), The cost of love: financial consequences of insecure attachment in antisocial youth. J. Child Psychol. Psychiatr. 60: 1343-1350 doi: 10.111/jcpp.13103.

\section{See also:}

Steele, H. (2019), Commentary: Money can't buy you loVe, but lack of love costs families and society plenty - a comment on Bachmann et al. (2019). J. Child Psychol. Psychiatr. 60: 1351-1352. doi: 10.111/ jcpp.13111.

\section{Glossary:}

Avoidant/dismissive behaviour: Affected children and infants are typically dismissive of close relationships and maintain an emotional distance between themselves and others. These children might also have difficulty seeking comfort from others when emotionally distressed.

\section{Resistant/preoccupied behaviour: Affected} children and infants are typically excessively distressed when separated from a caregiver but are not consoled when the caregiver returns. Rather, the distress can continue in the form of crying or tantrums. The child might also exhibit angry behaviour towards the caregiver, due to distrust that the caregiver is a secure base.

Disorganized behaviour: Affected children and infants exhibit ambivalent or unusual behaviour towards a caregiver. For example, a child might seek out and run toward a caregiver only to run away again or fight with the caregiver.

\section{References:}

'Bowlby, J. Attachment (1969) separation (1973) loss (1980). Trilogy of books. London: Penguin Books.

${ }^{2}$ Fearon, F.P. et al. (2010), The significance of insecure attachment and disorganization in the development of children's externalizing behavior: A meta-analytic study. Child Dev. 81: 435-456. doi: 10.1111/j.1467-8624.2009.01405.x

${ }^{3}$ Target, M. et al. (2003), Attachment representations in school-age children: the early development of the Child Attachment Interview (CAI). J. Child Pyschother. 29:171-186. doi: $10.1080 / 0075417031000138433$.

4Parsonage, M. et al. (2014). Building a better future: The lifetime costs of childhood behavioural problems and the benefits of early intervention. London: Centre for Mental Health. Accessible from: https://www.centreformentalhealth.org.uk/ sites/default/files/2018-09/buildingabetterfuture. pdf

${ }^{5}$ Scott, S. et al. (2001). Financial cost of social exclusion: Follow up study of antisocial children into adulthood. BMJ, 323, 191. doi: 10.1136/ bmj.323.7306.191. 